\title{
Antimicrobial Resistance and Production of Biofilms in Clinical Isolates of Coagulase-Negative Staphylococcus Strains
}

\author{
María Cristina Gaudioso de Allori, María Ángela Jure, Cintia Romero, and \\ Marta Elena Cecilia de CASTILlo* \\ Cátedra de Bacteriología, Instituto de Microbiología "Luis C. Verna", Facultad de Bioquímica, Química, Farmacia y \\ Biotecnología, Universidad Nacional de Tucumán; Ayacucho 491, San Miguel de Tucuman (4.000), Argentina. \\ Received November 16, 2005; accepted May 7, 2006
}

Coagulase-negative Staphylococcus (CNS) strains are frequently associated with bacteremia and hospital-acquired infections. 293 CNS strains were isolated from 744 samples from a dialysis center in S. M. de Tucumán, Argentina, from hemocultures, catheters and urine and identified as $S$. epidermidis, $S$. haemolyticus, $S$. saprophyticus, $S$. hominis and $S$. cohnii. 13 antibiotics were tested for antibacterial resistance. $75 \%$ of $S$. saprophyticus, $66 \%$ of $S$. epidermidis and $57 \%$ of $S$. haemolyticus was resistant to erythromycin and $50 \%$ of $S$. haemolyticus was resistant to ciprofloxacin. OXA resistance was found in $43 \%$ of $S$. haemolyticus. Presence of PBP 2 a in OXA-R strains was confirmed with the modified agglutination assay (MRSA) and presence of the mec $A$ gene. 15 strains with intermediate halos for vancomycin and teicoplanin showed a MIC in solid and liquid medium $\leq 1 \mu \mathrm{g} / \mathrm{ml}$ and $\leq 4 \mu \mathrm{g} / \mathrm{ml}$ respectively, which means that they were susceptible. $30 \%$ of the CNS strains produced biofilms: $42 \%$ of $S$. haemolyticus and $40 \%$ of $S$. epidermidis. $76 \%$ of the $S$. epidermidis and $59 \%$ of the $S$. haemolyticus biofilmproducing strains were isolated from catheters. The disc-diffusion technique together with the agglutination assay proved to be fast and reliable, which is of essential importance in intensive care units. Rapid identification of CNS strains, detection of resistance to methicillin and biofilm production are decisive for a prompt and appropriate antimicrobial therapy and limited use of inappropriate glycopeptides.

Key words coagulase-negative Staphylococcus; antimicrobial resistance; biofilm

Coagulase-negative Staphylococcus (CNS) strains are frequently associated with bacteremia and hospital-acquired infections, particularly in patients with catheters or other plastic devices. They include a great variety of species such as $S$. epidermidis, $S$. hominis, $S$. haemolyticus, $S$. saprophyticus, $S$. simulans and $S$. warneri, which have shown increasing resistance to antibiotic treatment, mainly to penicillin and synthetic $\beta$-lactams represented by oxacillin. Many of these oxacillin-resistant microorganisms (OXA-R) also present resistance to other antimicrobes, thus limiting the use of glycopeptides like vancomycin and teicoplanin. Staphylococcus isolations with reduced susceptibility to vancomycin have been described. ${ }^{1-3)}$

OXA-R CNS strains posses the mecA gene, which codes for a modified $78-\mathrm{kDa}$ protein, PBP $2 \mathrm{a}$, which is responsible for the resistance to $\beta$-lactams such as dicloxacillin, methicillin, nafcillin and oxacillin. The protein is able to bind to these antibiotics with very low affinity. The presence of the $m e c A$ gene in Staphylococcus strains is a synonym for OXA$\mathrm{R}$ and so the NCCLS (National Committee for Clinical Laboratory Standards) recommends that OXA-R CNS strains isolated from patients with serious infections should be tested for the mecA gene or PBP 2a presence. ${ }^{4,5}$

Biofilms are microbial communities wrapped in a matrix of exo-polysaccharides produced by the bacteria, which are adhered to an inert surface. This property becomes important in immunocompromised patients, because it produces chronic infections. S. epidermidis is thus far the most well known biofilm producer. ${ }^{6,7)}$

Little is known about the mechanism of resistance $(\mathrm{R})$ to antimicrobial agents in bacterial biofilm producers but apparently it limits antimicrobial diffusion and induces physiological alterations associated with low bacterial growth and the appearance of atypical phenotypes in these cells. ${ }^{8-15)}$
The objectives of the present paper were to detect mechanisms of antimicrobial resistance and biofilms production in clinical isolates of CNS strains.

\section{MATERIALS AND METHODS}

CNS Identification 293 CNS strains were isolated from 744 samples from a dialysis center in S. M. de Tucumán, Argentina: $156(53 \%)$ from urine, $107(37 \%)$ from catheters and $30(10 \%)$ from hemocultures. The bacteria isolated were characterized with conventional biochemical methods: catalase, bacitracin susceptibility and coagulase testing. The scheme proposed by Kloos and Schleifer, 1986, was used, which allowed identification of the CNS strains with the following tests: novobiocin resistance; urea hydrolysis; fermentation of: sucrose, xylose, maltose, trehalose, mannitol, cellobiose and raffinose; phosphatase; nitrate reduction and use of arginine. ${ }^{16,17)}$

Susceptibility to Antimicrobial Agents Antimicrobial sensitivity was carried out with the disc-diffusion technique in solid medium according to the NCCLS. The following antimicrobial agents were assayed: oxacillin (OXA) $1 \mu \mathrm{g}$, vancomycin (VAN) $30 \mu \mathrm{g}$, teicoplanin (TEI) $30 \mu \mathrm{g}$, gentamicin (GEN) $10 \mu \mathrm{g}$, ciprofloxacin (CIP) $5 \mu \mathrm{g}$, chloramphenicol (CMP) $30 \mu \mathrm{g}$, minocycline (MINO) $30 \mu \mathrm{g}$, ofloxacin (OFL) $5 \mu \mathrm{g}$, clindamycin (CLIN) $2 \mu \mathrm{g}$, erythromycin (ERY) $15 \mu \mathrm{g}$, tetracycline (TET) $30 \mu \mathrm{g}$, rifampin (RIF) $5 \mu \mathrm{g}$, trimethoprimsulfamethoxazole (TMS) $1.25 / 23.75 \mu \mathrm{g}$. ${ }^{\text {) }}$

Phenotypic Assays of the Resistance Mechanism a) Resistance to ERI-CLIN: The ERY-CLIN double disc method was used, which allows phenotypic detection of the inducible methylase (MLS) phenomenon, according to the HamiltonMiller methodology. This method consists of a flattening of the halo in the CLIN zone due to proximal inhibition pro- 
duced by the ERI disc. This indicates the presence of MLS and resistance to both ERI and CLIN. ${ }^{18,19)}$

b) Resistance to VAN and TEI: All strains with a halo $\leq 17 \mathrm{~mm}$ with VAN and $\leq 13 \mathrm{~mm}$ with TEI were screened on Blood-Heart-Infusion (BHI) agar plates with $6 \mathrm{mg} / 1$ of both VAN and TEI. The plates were inoculated with $10 \mu \mathrm{l}$ of a 0.5 McFarland suspension on the spot and incubated at $35^{\circ} \mathrm{C}$ for $24 \mathrm{~h}$.

In accordance with the NCCLS recommendations the MIC for VAN and TEI was assayed using the dilution method in liquid medium and on agar. MICs of $\leq 8 \mu \mathrm{g} / \mathrm{ml}$ (VAN) and $\leq 16 \mu \mathrm{g} / \mathrm{ml}$ (TEI) were considered as reduced susceptibility.

c) Resistance to $\beta$-Lactams: Of all the CNS strains that produced a halo $\leq 17 \mathrm{~mm}$ for OXA using the disc-diffusion method, the PBP 2a protein, a mecA gene product, was assayed.

The method consists of an agglutination assay with latex particles coated with monoclonal antibodies against the protein (Slidex MRSA detections). The assay was carried out following the manufacturer's instructions on the commercial kit, except for the following modifications: 3 and 6 loops of $1 \mu \mathrm{l}$ were used as inoculum and reading intervals were 3,6 and $15 \mathrm{~min}$. The assay was carried out with and without induction of oxacillin. ${ }^{20-22)}$

Genotypic Assays of the Resistance Mechanism Confirmation of oxacillin resistance was carried out by a polymer chain reaction (PCR) through detection of the mecA gene. ${ }^{23}$ )

Primers: The following primers were used: M1 and M2 that amplify a 310-bp fragment of the mecA gene, which codes for the PBP 2a protein, and DG74 and RW01 that amplify highly conserved regions of the 16S RNA, present in most pathogenic bacteria, obtaining a 370-bp fragment.

DNA Extraction: The template was prepared selecting 5 colonies of (all OXA resistant strains) to be assayed, which were resuspended in $150 \mu \mathrm{l}$ of $1 \%$ Triton $\times 100$ in TE buffer $\times 1$ or sterile bi-distilled water. This suspension was heated at $100^{\circ} \mathrm{C}$ for $10 \mathrm{~min}$ in a water bath and afterward centrifuged at $10000 \mathrm{rpm}$ for $5 \mathrm{~min}$. Five microliters of the supernatant were taken for further assays.

PRIMER: M1, TGGCTATCGTGTCACAATCG

PRIMER: M2, CTGGAACTTGTTGAGCAGAG

PRIMER: DG74, AGGAGGTGATCCAACCGCA

PRIMER: RWO1, AACTGGAGGAAGGTGGGGAT

PCR: The mixture selected for PCR consisted of $5 \mu \mathrm{l}$ of PCR buffer $10 \times$ (final concentration: $50 \mathrm{~mm} \mathrm{KCl,} 0.01 \%$ gelatin, $10 \mathrm{~mm}$ Tris- $\mathrm{HCl}$; $\mathrm{pH} 8.3), 1.5 \mathrm{~mm} \mathrm{MgCl}_{2}, 0.1 \mathrm{~mm} \mathrm{dNTP}$ (dATP, dCTP, dGTP and dTTP), $0.4 \mathrm{pmol} / \mu \mathrm{l}$ of each of the specific primers, $2 \mathrm{U}$ of tag polymerase and $5 \mu \mathrm{l}$ of the template to get a final reaction volume of $50 \mu \mathrm{l}$. All components were mixed in polystyrene tubes and subjected to amplification temperatures of the nucleic acid in a thermocycler.

DNA from the Joffre reference strain (methicillin resistant $S$. aureus obtained from the Antimicrobial Service of the Malbran Institute, Buenos Aires) was used as positive control of the reaction and sterile bi-distilled water as negative control. The mixture was initially denatured at $94^{\circ} \mathrm{C}$ for $5 \mathrm{~min}$ and then underwent 29 cycles of: $30 \mathrm{~s}$ at $94^{\circ} \mathrm{C}$ (denaturing), $30 \mathrm{~s}$ at $52^{\circ} \mathrm{C}$ (annealing) and $30 \mathrm{~s}$ at $72^{\circ} \mathrm{C}$ (extension). The reaction was finished with $5 \mathrm{~min}$ at $72^{\circ} \mathrm{C} .{ }^{24)}$ The amplification products were detected with agarose gel electrophoresis $(1 \%$ in TAE $1 \times$ buffer) at $80 \mathrm{~V}$ for $30 \mathrm{~min}$.
Biofilm Production Biofilm production was carried out with the micro method according to Pfaller et al. using radiation-sterilized, flat-bottomed, polystyrene multiple well plates for cell culture (polystyrene microtiter plate biofilm assay). Two biofilm-producing strains (263 and 1174) and a non-producing strain (ATCC 918) were used as controls. ${ }^{25}$ )

Brucella Agar (Difco) was used to maintain the strains at room temperature. They were cultured in BHI broth and incubated at $37^{\circ} \mathrm{C}$ for $18 \mathrm{~h}$ to initiate the assays. All the cultures were standardized through a standard dilution with $\mathrm{BHI}$ $\left(4^{\circ} \mathrm{C}\right)$ characterized by Experimental Transmittance $\mathrm{T}=30$, $\mathrm{OD}_{610}$. Growth was stopped at $4{ }^{\circ} \mathrm{C}$ by immersion in ice-cold water. From this standard dilution $50 \mathrm{ml}$ of a working suspension with corrected transmittance $\mathrm{T}=95(25 \mu \mathrm{l}$ of $\mathrm{T}=30$ en $5 \mathrm{ml}$ of refrigerated $\mathrm{BHI}$ ) was prepared. This dilution was kept at $4{ }^{\circ} \mathrm{C}$, thus assuring cellular quiescence.

Biofilm Production in Multiple Well Assay One hundred microliters of each bacterial suspension and the blank (BHI) were deposited in quadruplicate in each well, maintaining the plate quiet at $37^{\circ} \mathrm{C}$ during the incubation. The medium was extracted by inversion and washed twice with PBS buffer (8.1 mM Na $\mathrm{HPO}_{4}, 1.5 \mathrm{~mm} \quad \mathrm{KH}_{2} \mathrm{PO}_{4}, 140 \mathrm{~mm}$ $\mathrm{NaCl}$ and $3 \mathrm{~mm} \mathrm{KCl}$; pH 7.2). The contents were emptied by inversion and the plate was dried upside down on absorbent paper. Once dry, when the biofilm showed as a whitish and opaque membrane, it was fixed with methanol for $7 \mathrm{~min}$ (Christensen, 1985). The plate was emptied again by inversion and it was dried in the air. When it was dry it was dyed with a watery solution of $0.1 \%$ safranine. After 4 min the plate was inverted, washed with water and after inversion it was left to dry. ${ }^{26)}$

Reading was carried out through an ELISA reader at $490 \mathrm{~nm}$. Reading means were analyzed for each strain and they were compared with the blank in order to define the biofilm production. BHI was used as reading blank and the value for determining negative or positive was established calculating the standard deviation of the blank.

\section{RESULTS}

Identification: The $293 \mathrm{CNS}$ isolates were identified as: $S$. epidermidis $(37 \%, 32 \%, 15 \%)$, S. haemolyticus $(13 \%, 25 \%$, $35 \%)$, S. saprophyticus $(0 \%, 7 \%, 20 \%)$, S. hominis $(10 \%$, $5 \%, 15 \%)$, S. cohnii $(6 \%, 0 \%, 28 \%)$ from hemocultures, catheters or urine respectively (Fig. 1).

Resistance Patterns: Resistance profiles of the CNS strains against the 13 antibiotics assayed are presented in Table 1. Resistance to ERY was found in $75 \%$ of $S$. saprophyticus, $67 \%$ of $S$. epidermidis and $57 \%$ of $S$. haemolyticus and inducible methylase was found in $50 \%$ of $S$. saprophyticus, $17 \%$ of $S$. epidermidis and $54 \%$ of S. haemolyticus (Table 1).

Resistance to TET was observed in $50 \%$ of $S$. epidermidis and $43 \%$ of $S$. haemolyticus and $50 \%$ of the latter was resistant to CIP, whereas $S$. cohnii and $S$. epidermidis showed low resistance: less than $15 \%$ of the strains to CIP. S. saprophyticus showed high susceptibility to TMS, CIP, GEN, OXA, TET, VAN, TEI, RIF, CMP, OFL and MINO. Of all the strains studied only 15 demonstrated intermediate halos for VAN and TEI, but none of these grew on screening plates and the MIC in solid and liquid medium was less than $1 \mu \mathrm{g} / \mathrm{ml}$ and less than $4 \mu \mathrm{g} / \mathrm{ml}$ respectively, thus proving that 


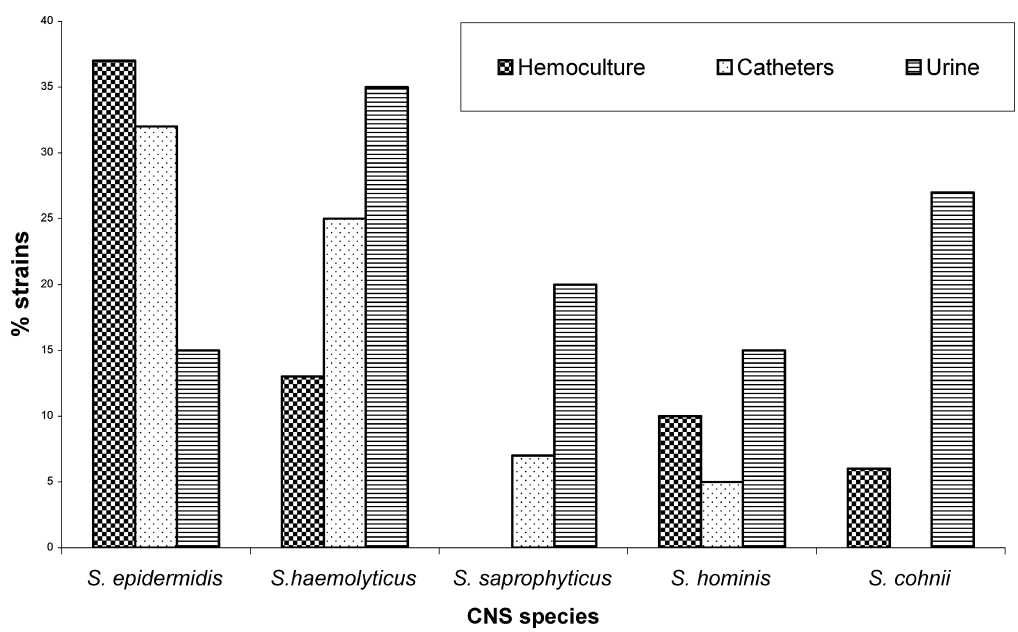

Fig. 1. Distribution According to Origen of the 293 Coagulase-Negative Staphylococcus (CNS) Strains Isolated from Dialysis Patients

Table 1. Resistance Profile of 293 CNS Strains against 13 Antimicrobial Agents, Using the Disc-Diffusion Technique

\begin{tabular}{|c|c|c|c|c|c|c|c|c|c|c|c|c|c|c|}
\hline \multirow{2}{*}{ Species } & \multicolumn{13}{|c|}{ Antimicrobial resistance (\%) } & \multirow{2}{*}{$\begin{array}{c}\text { Inducible } \\
\text { methylase } \\
\text { MLS }\end{array}$} \\
\hline & TMS & CIP & GEN & OXA & CLIN & ERY & TET & VAN & TEI & RIF & CMP & OFL & MINO & \\
\hline S. epidermidis & 17 & 10 & 17 & 16 & 17 & 67 & 50 & 0 & 0 & 11 & 50 & 0 & 8 & 17 \\
\hline S. haemolyticus & 29 & 50 & 43 & 43 & 50 & 57 & 43 & 0 & 0 & 0 & 36 & 25 & 8 & 54 \\
\hline S. hominis & 17 & 6 & 17 & 17 & 17 & 37 & 0 & 0 & 0 & 17 & 0 & 17 & 83 & 18 \\
\hline S. cohnii & 18 & 15 & 18 & 18 & 27 & 36 & 36 & 0 & 0 & 17 & 0 & 12 & 9 & 17 \\
\hline S. saprophyticus & 0 & 0 & 0 & 0 & 75 & 75 & 0 & 0 & 0 & 0 & 0 & 0 & 0 & 50 \\
\hline
\end{tabular}

TMS (trimethoprim-sulfamethoxazole 1.25/23.75 $\mu \mathrm{g}$ ), CIP (ciprofloxacin: $5 \mu \mathrm{g}$ ), GEN (gentamicin: $10 \mu \mathrm{g}$ ), OXA (oxacillin: $1 \mu \mathrm{g}$ ), CLIN (clindamycin: $2 \mu \mathrm{g}$ ), ERY (erythromycin: $15 \mu \mathrm{g}$ ), TET (tetracycline: $30 \mu \mathrm{g}$ ), VAN (vancomycin: $30 \mu \mathrm{g}$ ), TEI (teicoplanin: $30 \mu \mathrm{g}$ ), RIF (rifampin: $5 \mu \mathrm{g}$ ), CMP (chloramphenicol: $30 \mu \mathrm{g}$ ), OFL (ofloxacin: $5 \mu \mathrm{g}$ ) MINO (minocycline: $30 \mu \mathrm{g}$ ), and MLS (inducible methylase).

all the CNS strains assayed were sensitive to these antimicrobes.

Those strains that were resistant to OXA showed a diameter of the bacterial growth inhibition less than $17 \mathrm{~mm}$. With the agar diffusion method OXA resistance was detected in $43 \%$ of $S$. haemolyticus, $18 \%$ of $S$. cohnii and in $16 \%$ of $S$. epidermidis and $17 \%$ of $S$. hominis. Presence of PBP 2 a was confirmed in all OXA resistant strains with the agglutination assay. It could be observed that with a longer incubation time and higher initial inoculation sensitivity of the method increased as well as the OXA-induced strains.

PCR confirmed the presence of the mecA gene in all CNS strains with OXA resistance observed with phenotypic techniques. There was no discrepancy between the disc-diffusion technique and MRSA agglutination, observing excellent sensitivity and specificity.

From all the assays carried out $S$. haemolyticus was the species with the highest resistance profile.

Biofilm Production: $30 \%$ of the 293 CNS strains assayed produced biofilms: $42 \%$ of $S$. haemolyticus, $40 \%$ of $S$. epidermidis, $29 \%$ of $S$. saprophyticus and $12 \%$ of $S$. cohnii, but none of the $S$. hominis strains. Of all the biofilm-producing strains $76 \%$ of $S$. epidermidis and $59 \%$ of S. haemolyticus were isolated from catheters; the remaining $24 \%$ and $41 \%$ respectively were from urine samples. No biofilm-producing CNS strain was isolated from hemocultures (Table 2).

The results showed that in $S$. haemolyticus and S. epidermidis the biofilm-producing strains presented a high percentage of resistance to two or more antibiotics: 29 strains out of 37 biofilm-producing S. haemolyticus (78\%), and 20 strains
Table 2. Five Biofilm-Producing Coagulase-Negative Staphylococcus (CNS) Species (Comprising 160 out of 293 Isolated Strains) and Their Origin (Uroculture, Catheter or Hemoculture)

\begin{tabular}{|c|c|c|c|c|c|}
\hline \multirow{2}{*}{ Species } & \multirow{2}{*}{$\begin{array}{c}\text { Number } \\
\text { of } \\
\text { strains } \\
n=293\end{array}$} & \multirow{2}{*}{$\begin{array}{c}\text { Biofilm- } \\
\text { producing } \\
\text { strains } \\
n=88\end{array}$} & \multicolumn{3}{|c|}{$\begin{array}{c}\text { Origin of } \\
\text { biofilm-producing strain }\end{array}$} \\
\hline & & & Uroculture & Catheter & Hemoculture \\
\hline S. hemolyticus & 88 & $37(42 \%)$ & $15(41 \%)$ & $22(59 \%)$ & 0 \\
\hline S. epidermidis & 73 & $29(40 \%)$ & $7(24 \%)$ & $22(76 \%)$ & 0 \\
\hline S. cohnii & 59 & $7(12 \%)$ & $7(100 \%)$ & 0 & 0 \\
\hline S. saprophyticus & 51 & $15(29 \%)$ & $15(100 \%)$ & 0 & 0 \\
\hline S. hominis & 22 & 0 & 0 & 0 & 0 \\
\hline
\end{tabular}

Table 3. Classification of Biofilm-Producing Coagulase-Negative Staphylococcus (CNS) Strains and Their Resistance to Two or More Antimicrobial Agents

\begin{tabular}{lcc}
\hline \hline \multicolumn{1}{c}{ Species } & $\begin{array}{c}\text { Biofilm-producing } \\
\text { strains } \\
n=88\end{array}$ & $\begin{array}{c}\text { Resistance to 2 or more } \\
\text { antimicrobial agents } \\
n=88\end{array}$ \\
\hline \hline S. haemolyticus & 37 & 29 \\
S. epidermidis & 29 & 20 \\
S. cohnii & 7 & 15 \\
S. saprophyticus & 15 & 24 \\
\hline
\end{tabular}

out of 29 S. epidermis (69\%) showed resistance to two or more antimicrobial. This correlation was not observed in $S$. cohnii and S. saprophyticus (Table 3 ).

$S$. haemolyticus was the highest biofilm-producing strain 
and the species that revealed the highest percentage of resistance to the antibiotics assayed.

\section{DISCUSSION}

Although there exist about 20 CNS species only a few of them have been associated with an increase in hospital-acquired infections due to the use of invasive elements. Numerous authors have suggested the need to identify and characterize the species so as to find out the most frequently isolated ones and their association with different degrees of resistance. ${ }^{27,28)}$

Finelli et al. reported in a survey with dialysis patients carried out in 2002 that 40 to $60 \%$ of the infections was caused by CNS species. ${ }^{29)}$

The National Reference Laboratory for Staphylococcus in the U.S.A., directed by Dr. Peter Petras, reports that the isolated CNS strains from clinical samples from human origin are $S$. epidermidis (30\%), S. hominis (14\%) and S. haemolyticus $(14 \%){ }^{30)}$

Worthington et al., identified from 56 CNS strains isolated from catheters $54 \mathrm{~S}$. epidermidis, $1 \mathrm{~S}$. lugdunensis and $1 \mathrm{~S}$. hominis. Similarly, De Paulis et al., reported that the isolated CNS strains were: S. epidermidis (51\%), S. haemolyticus (18\%), S. saprophyticcus (16\%), S. lugdunensis (6\%) and S. warneri $(2 \%)$. The results obtained in our study are similar to those of the aforementioned authors coinciding with the fact that the most frequently isolated CNS strain was $S$. epidermidis, followed by $S$. haemolyticus and $S$. hominis. ${ }^{31,32)}$

Antibiotic susceptibility studies are very important from an epidemiological point of view, because they allow establishing policies for adequate and rational use of antibiotics, thus increasing the quality of attention toward the patient, protecting the lifespan of these drugs and giving economic benefits.

Resistance to antibiotics both in hospitals and the community is an increasing problem in medical treatment. Of particular interest are methicillin resistant (Meth R) Staphylococci that carry $\mathrm{R}$ genes to other antibiotics such as ERY, TET, streptomycin, TM, GEN and Sulfonamides. ${ }^{33)}$

Louis et al. and Archer, have pointed out the importance to distinguish between $S$. aureus and CNS in clinical samples and their behavior toward antimicrobial agents in order to implement a fast and appropriate antimicrobial treatment. ${ }^{16,34)}$

Prevalence of methicillin-resistant Staphylococci in hospital-acquired infections has increased during the last decade, as well as in community-acquired infections in patients without any clear risk. ${ }^{35)}$

Garrett et al. detected and characterized CNS strains with diminished susceptibility to VAN and Sierazki et al. detected resistant strains. Failures in the treatment with VAN have been described in Japan and the U.S.A. In a survey in France $23 \%$ of $362 \mathrm{CNS}$ strains presented intermediate resistance to TEI; $74 \%$ of the resistant strains was identified as $S$. epidermidis and $19 \%$ as $S$. haemolyticus. ${ }^{36-38)}$

In Virginia, $13 \%$ of $S$. haemolyticus strains isolated during a period of 10 years showed resistance to VAN and $62 \%$ of the isolates had a MIC superior to $6.25 \mu \mathrm{g} / \mathrm{ml} .{ }^{39)}$ Our results demonstrated methicillin resistant CNS strains, but no resistance or diminished susceptibility to glycopeptides was ob- served.

In Havana, Cuba, González et al. detected presence of MLS phenotype in $17 \%$ of the strains, $28 \%$ of which belonged to $S$. aureus and $5 \%$ to a CNS strain. ${ }^{40)}$ The results obtained in our study showed that $45 \%$ of the CNS isolates presented this phenomenon with a higher incidence in $S$. haemolyticus and $S$. saprophyticus: 54 and 50\% respectively.

Several authors have observed the presence of a mecA gene in different CNS strains and its correlation with resistance to OXA. However, there have been discrepancies between the genetic results of the presence of the mecA gene with phenotypic assays (disc-diffusion) and MIC for resistance top OXA. Recently, the disc-diffusion assay for OXA has been questioned. ${ }^{21,34,41)}$

The results in our study coincide with the PBP 2a detection with slidex MRSA and detection of the mecA gene showing $100 \%$ specificity, which agrees with the results by Corso et al. ${ }^{20)}$

Although trimethoprim is no drug of choice for Staphylococci treatment it is used in combination with sulfamethoxazole to achieve effective treatments in patients infected with multi-resistant Staphylococci. Studies carried out by González et al. showed resistance of CNS strains to TM. Between 0 and $29 \%$ of our strains were resistant to TMS. Our results with ERY, VAN and TEI were similar to those obtained by Barberis et al. but resistance to TET and CIP was higher. $^{40,45)}$

Since Staphylococci belong to the normal flora of the skin, interpretation of their isolation is a great challenge to the microbiologist. They must evaluate the significance of their findings through detection of biofilm-producing strains, because there do not exist reliable markers that allow identification of pathogens. ${ }^{42)}$

Staphylococcus is a bacterial pathogen that usually produces biofilms during different infectious processes, which are generally chronic and difficult to treat. As a result, higher doses of antibiotics are needed or sometime a prolonged period of administration to eliminate the plantonic bacteria of exactly the same strain. ${ }^{43)}$

It is well known that a microorganism that is sensitive in vitro might be unaffected in vivo. In human medicine it has been estimated that $65 \%$ of the hospital-acquired infections is associated to a biofilm and that they are 10 to 1000 times more difficult to eliminate with an otherwise successful treatment. $^{5,42,44)}$

Infection is an important complication of patients undergoing dialysis and 40 to $60 \%$ is due to CNS strains. Barberis et al. have published about biofilm production in CNS strains associated to human infections and their results are similar to ours. ${ }^{45)}$

Rapid identification of CNS strains and detection of resistance to methicillin are essential for a prompt and appropriate antimicrobial therapy and limited use of inappropriate glycopeptides.

Sensitivity and specificity of the PCR technique applied in our study for detection of the mecA gene in CNS strains was comparable with phenotypic methods. Consequently, it may be concluded that due to the equipment and supplies needed for PCR, the disc-diffusion technique together with agglutination can be used as a reliable alternative for fast results, especially necessary in intensive care units. 
In our study the CNS strains presented a significant association between biofilm production and resistance to a variety of antimicrobial agents, mainly $S$. haemolyticus, which was the species with the highest biofilm production and antimicrobial resistance. It is important to detect biofilm-producing bacteria in order to implement an appropriate antimicrobial therapy at an early stage. ${ }^{46}$

Our results confirm that the CNS strains isolated in the Tucumán area possess high resistance to methicillin and most of them are resistant to two or more antibiotics. Besides, they frequently produce biofilms in infections associated with dialysis patients.

\section{REFERENCES}

1) Goldmann D. A., Weinstein R. A., Wenzel R. P., Tablan O. C., Duma R. J., Gaynes R. P., Schlosser J., Martone W. J., JAMA, 275, 234-240 (1996).

2) Shanson D. C., Johnstone D., Midgley J., J. Hosp. Infect., 6, 285-292 (1985).

3) Sieradzki K., Richard B., Robert M. D., Stuart W., Haber M. D., Tomasz A., Brief Report., 340, 517-523 (1999).

4) Hackbarth Corinne Kocagoz T., Chamers H., Antimicrob. Agents Chemother, 39, 103-106 (1995).

5) National Committee for Clinical Laboratory Standards (NCCLS). Performance Standards for Antimicrobial Susceptibility Testing. Eleventh Informational Supplement NCCLS approved standard M 100-S11. National Commitee for Clinical Laboratory Standards, Wayne, PA., Vol. 21, No. 1, 2001.

6) Donlan R., Costerton W., Clin. Microbiol. Rev., 15, 167-192 (2002).

7) Rupp M., Ulphani J., Fey P., Mack D., Infect. Immun., 67, 2656-2659 (1999).

8) Anwar H., Strap J., Costerton J. W., Antimocrob. Agents Chemother, 36, 1347-1351 (1992).

9) Brown M. R. W., Gilbert P., J. Appl. Bacteriol., 74 (Suppl. 1), S87S97 (1993).

10) Costerton J. W., Stowart P. S., Greenberg E. P., Science, 284, 1318 1822 (1999).

11) Costerton J. W., Lewandowski Z., Caldwell D. E., Korder D. R., Lappin-Scott H. M., Ann. Rev. Microbiol., 49, 711-745 (1995).

12) Farber B. F., Kaplan M. H., Glogston G., J. Infect. Dis., 161, 37-40 (1990).

13) Hoyle B. D., Alcantara J., Costerton J. W., Antimicrob. Agents Chemoter, 36, 2054-2056 (1992).

14) Kumon H., Tomochika K., Matumaga T., Ogawa M., Ohmori H., Microbiol. Immunol., 38, 615-619 (1994).

15) Shigeta M., Komatsuzawa H., Sugai M., Suginaka H., Usui T., Chemotherapy, 43, 137-141 (1997).

16) Archer G. L., "Principles and Practice of Infectious Diseases," ed. by Mandell G. L., Douglas R. G., Jr., Bennett J. E., Churchill Livingstone, New York, 1999, pp. 1511-1518.

17) Kloos W. E., Schleifer K. H., Bergey's Manual of Systemic Bacteriology, Vol. 2, ed. by Smeath P. H. A., Mair N. S., Sharpe M. E., Holt J. G., American Society for Microbiology, Washington DC, 1986, pp. 1013-1035.

18) Duval J., J. Antimicrob. Chemother, 16 (Suppl. A), 137-149 (1985).

19) Eliopulos G. M., Moellering R. C., Antibiotics in Laboratory Medicine, $3^{\circ}$ ed., ed. by Lorian V., The Williams \& Wilkins, Co., Baltimore,
1991, pp. $432-492$.

20) Corso A., Soloaga R., Faccone D., Gagetti P., Corbella S., Iglesias S., Galas M., Diagn. Microbiol. Infect. Dis., 50, 223-225 (2004).

21) Hussain Z., Stoakes L., Lannigan R., Longo S., Nancekivell B., J. Clin. Microbiol., 36, 273-274 (1998).

22) Nakatomi Y., Sugiyama J., Microbiol. Inmunol., 41, 739-743 (1998).

23) Mason W. J., Blevins J., Beenken K., Wibowo N., Ojha N., Smeltzer M., J. Clin. Microbiol., 2001, 3332-3338 (2001).

24) Van Nuffel P., Gigi J., Ezzeddine H., Vandercam B., Delmee M., Wauters G., Gala J., J. Clin. Microbiol., 33, 2864-2867 (1995).

25) Pfaller M., Davenport D., Bale M., Koontz F., Massanari R. M., Eur. J. Clin. Microbial. Infect. Dis., 7, 30-33 (1988).

26) Christensen G., J. Clinical Microbiol., 1985, 956-1006 (1985).

27) Diekema D. J., Pfaller M. A., Schmitz F. J., Smayevsky J., Bell J., Jones R. N., Beach M., Clin. Infect. Dis., 32 (Suppl. 2), S114-S132 (2001).

28) Weistein M. P., Mirrit S., Van Pelt L., McKinnon M., Zimmer M., Kloos B. L., Reller L. B., J. Clin. Microbiol., 36, 2089-2092 (1998).

29) Finelly A., Burrows L., DiCosmo F., DiTizio V., Sinnadurai S., Oreopulos D., Khoury A., Peritoneal Dialysis International, 22, 27-31 (2002).

30) Petras P., National Reference Laboratory for Staphylococci. National Institute of Public Health, building 2, $2^{\circ}$ floor, Laboratory $\mathrm{N}^{\mathrm{a}} 15^{\mathrm{a}}, 22 \mathrm{~b}$. 1998.

31) De Paulis A., Predari S., Chazarreta C., Santoiani J., J. Clin. Microbiol., 41, 1219-1224 (2003).

32) Worthington T., Lambert P. A., Elliot T. S., J. Hosp. Infect., 46, 130134 (2000).

33) Dale G., Hanno L., Page M., Then R., Stüber D., Antimicrob. Agents Chemother, 39, 1920-1924 (1995).

34) Louie L., Goodfellow J., Mathieu P., Glatt A., Louie M., Simor A. E., J. Clin. Microbiol., 40, 2786-2790 (2002).

35) Center for Disease Control and Prevention NNIS System. National nosocomial infections surveillance (NNIS) system report, data summary from January 1992-June 2001 issued August 2001. Am. J. Infect. Control., 28, 404-421 (2001).

36) Garrett D. O., Jochimsen E., Murfitt K., Hill B., McAllister S., Nelson P., Spera R. V., Sall R. K., Tenover F. C., Johnston J., Zimmer B., Jarvis W. R., Infect. Cont. Hosp. Epidemiol., 20, 167-170 (1999).

37) Laboratory Detection of Coagulase-negative Staphylococcus species with decreased susceptibility to the glycopeptides Vancomicin and Teicoplanin, CDC, Department of Health and human Services, U.S.A., 1999.

38) Tenover F. C., Lancaster M. V., Hill B. C., Steward C. D., Stocker S A., Hancock G. A., O’Hara C. M., McAllister S. K., Clark N. C., Hiramatsu K., J. Clin. Microbiol., 36, 1020-1027 (1998).

39) Froggatt J. W., Johnston J. L., Galetto D. W., Archer G. L., Antimicrob. Agents Chemother, 33, 460-466 (1989).

40) González I., Niebla A., Roura G., González L., Travieso F., Lemus M., Contreras R., Vallin C., Rev. Panam. Inf., 5, 30 (2002).

41) Huang M. B., Gay T. E., Baker C. N., Banerjee S. N., Tenover F. C., J. Clin. Microbiol., 31, 2683-2688 (1993).

42) Rupp M. E., Archer G. L., Clin. Infect. Dis., 19, 231-245 (1994).

43) Costerton, Bill. Biofilms..a growing problem. Sanitation and safety supplies. Seminar transcript., Kingston, Ontario, Canada, 2000, p. $1-$ 30.

44) Rupp M. E., Archer G. L., Infect. Immun., 60, $4322-4327$ (1992).

45) Barberis I., Pájaro M. C., Godino S., Pascual L., Daniele M., Rev. Latinoam. De Microbiol., 43, 109-113 (1999).

46) Souli M., Giamarellou H., Antimicrob. Agents Chemother., 42, 939941 (1998). 